\title{
Corporate and Governmental Responsibilities for Preventing Chemical Disasters: Lessons from Bhopal
}

\author{
Ingrid Eckerman and Tom Børsen
}

\begin{abstract}
In the evening of December $2^{\text {nd }}, 1984$, a series of unfortunate events led to 43 tons of methyl isocyanate being vaporized and spread over the city of Bhopal in central India. The accident, which continued throughout the early hours of December $3^{\text {rd }}$, resulted in the deaths of several thousand people and left hundreds of thousands more with permanent injuries. The Bhopal toxic leakage is widely regarded as the largest chemical industrial disaster in the world. It is also one of the most publicly scrutinized disasters, leading to vivid evidence about the threat to public health posed by the chemical production industry. This paper argues that Union Carbide Corporation, through its local subsidiary Union Carbide India Limited, as well as the governments of India and Madhya Pradesh, are those who were most accountable for the leakage. Furthermore, the paper shows that several ethical rules such as: the Golden Rule, the human rights to safety, the precautionary principle, and the principles for a sustainable society were violated. In the final sections, the paper discusses the measures that should be taken to prevent future exposure to toxic chemical substances which may occur due to accidents at chemical production facilities.
\end{abstract}

Keywords: Bhopal disaster, chemical industry, methyl isocyanate (MIC), corporate ethics, sustainability, buman rights.

\section{Introduction}

The gas leakage from the Union Carbide plant in Bhopal, India, in 1984 is the largest industrial chemical accident to have ever occurred in the world. Over 500,000 people were exposed to poisonous gases, resulting in between 3,000 and 10,000 people dying within the first weeks of the accident and between 100,000 and 200,000 being left with possible permanent injuries. Due to its magnitude, the catastrophe remains one of chemistry's most important ethical cases - the lessons of which should never be forgotten by practitioners of 
chemistry or by any other individuals involved in the production of potentially dangerous compounds.

In the aftermath of the disaster, volunteers and journalists quickly invaded Bhopal's Old Town resulting in a large quantity of documented information about the event. Interviews with employees, health care staff, and inhabitants were published in newspapers and collected by non-governmental organizations. A mine of detailed material, intended solely for internal use, was made public. This depth of investigation resulted in specific details regarding the procedures which led to the leakage (such as the effects of the gases and the actions of the company, the government, and the medical and scientific establishments) being recorded within thousands of articles, reports, books, and films. For example, the reference list for the book The Bhopal Saga alone contains some 200 items (Eckerman 2005b). Activists, volunteers, and survivors continue their investigations and battle for justice even after more than 30 years since the accident.

The investigations illustrate the threat to public health posed by the chemical industry. They highlight how decision-makers, citizens, and sometimes even the experts themselves are unaware of the dangers of the chemical compounds that they might be exposed to due to accidents at chemical plants. The responsible parties do not know how, or to what degree, these compounds might be harmful to themselves either in the short or long term. The case also illustrates the roles played by transnational companies, and how they often succeed in influencing decisions made at the regulative level. These mechanisms are not only confined to less developed countries, but are also found in the so called 'richer' countries.

In relation to minimizing the risk of industrial hazards, three main actors can be identified: companies, governments, and the civil society (which in this case is represented by trade unions and other NGOs). The most powerful entities are the companies which have expertise and money. The governments, especially in low income countries, rely on these companies for economic development. The trade unions are mostly concerned about jobs, but also about the health of their workers. These, along with other nongovernmental organizations such as those protecting human rights and the environment, typically hold less power.

In the Bhopal case, the major actors identified are Union Carbide Corporation (UCC) and its subsidiary Union Carbide India Limited (UCIL); the Governments of India (GoI) and Madhya Pradesh (MP Gov); and, finally, the survivors' organizations and plant workers' trade unions. Each of these actors had several ethical aspects to consider which will be analyzed and discussed in this paper. The paper begins by providing a review of the catastrophe, based on the previously mentioned book (Eckerman 2005b). 


\section{Background}

\subsection{The green revolution}

During the 1950's, it was widely held that the expanding global population, particularly rapid in lower income countries, necessitated an increase in global food production. Therefore, increased global efforts to develop new agricultural techniques were made. Countries most regularly threatened by famine eagerly turned to solutions developed in the chemical industry to increase their own food production. In India, the introduction of synthetic fertilizers and pesticides were major developments in a wider reform of farming practices known as the 'green revolution'. A decade after colonial rule had come to an end, the Indian government also targeted foreign investment as being a key route to industrial development. Large corporations were encouraged to establish subsidiary companies within the country. The US owned Union Carbide Corporation (UCC) formed the subsidiary Union Carbide India Limited (UCIL), $50.9 \%$ of which was controlled by UCC with the remaining $49.1 \%$ being held by Indian investors, including the Government of India and government-controlled banks.

The company's pesticide plant was constructed in 1969 in Bhopal - a city located on a key railroad junction in the middle of the country with a nearby lake that acted as a source of fresh water. Being one of the first major foreign investment projects, the plant was regarded as the crown of Indian industrialism. The upper social strata of Bhopal were closely involved in the plant's activities while working for UCIL became a prestigious affair and offered an excellent salary, even for those on the lower social tiers.

Methyle isocyanate (MIC) was used as an intermediate in the production of carbamate pesticides (brandmark Sevin). To start with, MIC was imported from the US, but later a new plant for producing MIC was planned. The MP Government designated a zone southeast of the town that, due to the prevailing wind patterns, would specifically accommodate industries involved with dangerous substances. The MIC plant was at first directed to this area. However, an exception was made, and UCIL received the permission to build the MIC plant within the existing plant area close to the railway station in the Old Town. In 1980, the Bhopal plant started to manufacture MIC, applying knowledge and designs supplied from the parental company based in the USA. 


\subsection{MIC and its properties}

Between 1958 and 1973, Union Carbide used a method of producing the carbamate pesticide without using MIC (Figure 1b). For economic reasons, this was later changed to a more hazardous process (Chouhan 1994).

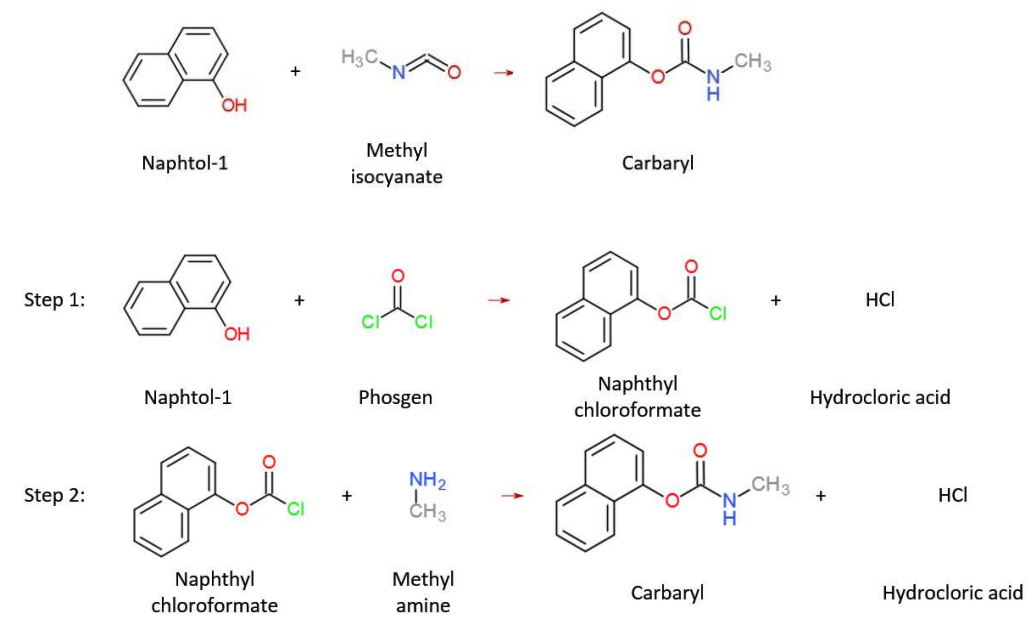

Figure 1: The production of Sevin (carbaryl): (a) direct pathway with MIC, (b) original pathway without MIC.

A run-away-reaction was described in the UCC manuals (UCC 1976, UCIL 1978):

Water reacts exothermically to produce heat and carbon dioxide. As a result, the pressure in the tank will rise rapidly if MIC is contaminated with water. This reaction may begin slowly, especially if there is no agitation, but it will become violent. [...] MIC reacts vigorously with contaminants such as water, acids, alkalis and amines and can polymerize rapidly if in contact with iron, steel, zinc, tin, galvanized iron, copper and its alloys.

Exposed to high temperatures, MIC breaks down to hydrogen cyanide (HCN) (Ramachandran 1994). Even small concentrations of HCN are known to kill people rapidly.

According to Jones (1988), UCC was well-aware of the effects of MIC. In the company's manual from 1976, the acute effects on health were described (UCC 1976):

MIC may cause severe or permanent injury when in contact with eyes or skin.

If inhaled or swallowed in sufficient quantities, death may result. MIC acts like tear-gas, but is (many times) more lethal. MIC is a poison by inhalation 
$[\ldots]$ and is intensely irritating to breathe. It causes severe bronchospasm and asthma-like breathing. [...] It should also be regarded as an oral and contact poison. Skin contact can cause severe burns. The liquid will seriously injure the eyes, even when it is diluted with a non-toxic liquid to a one percent concentration.

After the Bhopal leakage, UCC as well as some governmental scientists maintained that MIC cannot penetrate the lung-blood barrier and that it cannot lead to permanent injuries. They said that the chemical would neutralize itself immediately in the presence of moisture (National Institute for Working Life 2001). However, the Indian Council of Medical Research (ICMR) found MIC trimers, hydrogen cyanide, and other compounds in autopsy samples and maintains that this offers proof that different substances entered the body's system. A further study on methyl carbamylation in postmortem blood also supports this premise (National Institute for Working Life 2001).

\section{The Accident and Its Causes}

\subsection{The direct cause}

The specifics of the accident and its effects are described and remain contested in several books and reports including those released by Union Carbide (UCC 1985, Kalelkar 1988), Indian authorities (Varadarajan 1985), trade unions (ICFTU-ICEF 1985), non-governmental organizations (Delhi Science Forum 1985), foreign experts on disaster medicine (Kulling \& Lorin 1987) and former employees (Chouhan 1994). However, what is not disputed today is that during the evening of December $2^{\text {nd }}$, the supervisor on duty had been transferred from a different unit to the MIC-plant - a plant which he was not familiar with.

According to the account, the supervisor ordered a group of untrained workers to connect a water hose to the pipeline system and to let it run for several hours, but had forgotten to inform them to add a slip bind. Approaching midnight, a group of workers noticed the presence of MIC in the air and informed members of staff who deemed that no action was necessary as leakages were common. Shortly afterwards, the production tank began to rumble, the pressure reading started to rise, and the levels of MIC in the air increased. The staff gradually realized that something was very wrong and attempted to use the safety equipment to solve the issue, but failed. It was not until approximately 2 a.m. that the main alarm, directed towards the sur- 
rounding community, sounded. By that stage injured people had already started to enter the hospital.

While the account above has been mostly agreed upon, what remains disputed is the direct cause of the leakage. Union Carbide, now owned by DowDuPont, maintains that it was impossible that the water from the hose could have reached the tank. Instead, it was a disgruntled worker who had directed the water directly into the tank. The worker, who has since identified himself, has never been sued. Activists, on the other hand, argue that the worker would have died immediately. They cling to the idea that it was an extra jumper line that made it possible for the water to enter the production tank (Chouhan 1994).

\subsection{Deficient factory design}

A number of investigators identified deficiencies in the design of the MIC plant in Bhopal as having contributed to the accident. Researchers include Chouhan (1994), Delhi Science Forum (1985), Council of Scientific and Industrial Research (CSIR) (Varadarajan 1985) and the Disaster Management Institute (Ramachandran 1994).

At the Bhopal plant, a dangerous but cost-effective method of manufacturing of Sevin was chosen. Instead of storing MIC in many small barrels, or producing only small batches of MIC, as was the practice in the UCC plant in Virginia, it was stored long term in two large tanks. For economic reasons the factory in Bhopal was not provided with the required safety equipment or security systems that the engineers had envisaged (Lapierre \& Moro 2001). The safety features that were installed were under-dimensioned. Instead of using a computerized alarm system like that in the Virginia plant, the plant in Bhopal relied on manual operations. The poor staffing policy cut the training of unskilled employees and reduced the employment of people in skilled roles leading to inadequate safety management. Other areas of criticism focused on the poor maintenance of the plant and that no emergency response plans were in force (Eckerman 2005b).

After the leakage, UCC's first line of defense was that the equipment installed in Bhopal was made in the USA to US specifications, and that it included safety equipment and standards virtually identical to the Virginia plant (Jones 1988). However, due to a backlash by the teams in Virginia, UCC was forced to admit that this was not the case.

The MIC unit in Bhopal was over-dimensioned from the start and always run at a loss. The US manager was replaced by an Indian manager who was ordered to achieve cost savings. And so he did, by cutting down on safety. It is this report's opinion that as it was UCC that chose the design and was well 
represented on the UCIL board, the company can hardly avoid accepting responsibility for the safety status of the plant.

\subsection{Neglect of warning signals}

The UCIL hierarchy regarded the plant as "one of the safest ships in the modern fleet". The chief medical officer at Bhopal claimed that "the safety precautions we took were the best possible" and stated "We did everything the Americans advised. In fact, we used to think that we were overdoing the safety" (Jones 1988). The reality, however, is that leakages occurred regularly. The trade union distributed 6,000 posters warning about the dangers. A union leader went on hunger strike at the factory's entrance to highlight the risks. Meetings and processions were held in the city and a journalist wrote several articles in the local press to further highlight the dangers. However, neither UCIL nor the MP Gov took any notice. Instead of acting on the warning signals, the officials dismissed the union leaders. It appears that the management's views on safety differed from those of the workers.

Safety audits were completed every year in US and European UCC plants, but only every second year in other parts of the world (Jones 1988). As stated in a 'Business Confidential' safety audit by UCC in May 1982, the senior officials of the corporation were well aware of "a total of 61 hazards, 30 of them major and 11 minor in the dangerous phosgene/methyl isocyanate units" (UCC 1985). This audit expressed severe concerns about the poor state and inappropriate placement of safety equipment; the lack of periodic checks to see that the instruments and alarm systems were functioning correctly; an alarming turnover of inadequately trained staff; unsatisfactory instruction methods; and a lack of rigor in maintenance reports. However, the report ended by stating that "No situations involving imminent danger or requiring immediate correction were noted during the survey". Nevertheless, UCC admitted in their own investigation report (UCC 1985) that most of the safety systems were not functioning on the night of the accident. The report revealed that:

- Tank temperatures were not logged;

- The vent gas scrubber (VGS) was not in use;

- The cooling system was not in use;

- A slip bind disc, that would prevent the water to take the wrong way, was not inserted when the pipes were washed;

- The concentration of chloroform in the production tank was too high;

- The tank was not pressurized;

- Iron was present because of corrosion;

- The tank's high-temperature alarm was not functioning;

- The evacuation tank was not empty. 
Both the plant design and safety management were of a lower quality than that at UCC's other plants in US and Europe, meaning that UCC operated with a double set of safety standards. As a result, all the chemical conditions to cause the disaster were made present.

\subsection{Contents of the gas cloud}

Based on several reports (Varadarajan 1985, UCIL 1978, Subramaniam 1985, Kumar \& Mukerjee 1985), it is likely that at areas nearest the factory the cloud would have been mainly composed of MIC and trimers of MIC, but would also have contained hydrogen cyanide $(\mathrm{HCN})$, nitrogen oxides (NOX), carbon dioxide (CO2), and carbon monoxide (CO), all of which replaced the air (Figure 2). The released MIC, once in contact with the moisture in the air, would have been converted in the atmosphere into monomethyl amine (MMA) and carbon dioxide. It is improbable that cyanide $(\mathrm{CN})$ would have been widely dispersed.

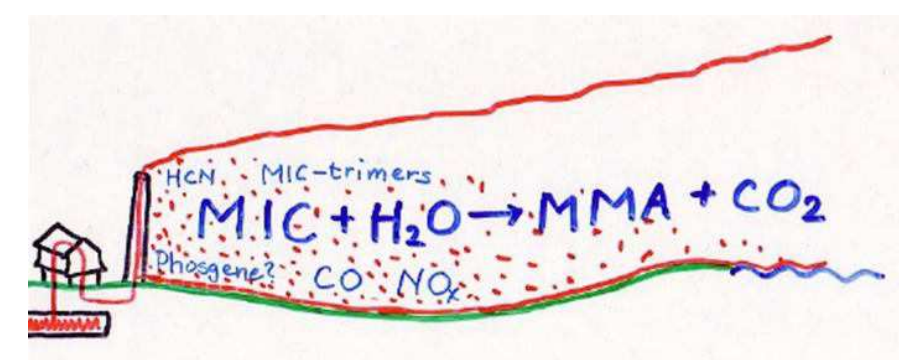

Figure 2. The suggested contents of the gas cloud (from Eckerman 2001).

\section{Effects of the Bhopal Accident}

\subsection{Short term effects}

The inhabitants of the surrounding neighborhood were awoken due to coughing, vomiting, a burning feeling in eyes and respiratory organs, and a feeling of suffocation. They attempted to flee from the plant - and thus ending up walking, running, and cycling in the same direction as the wind. Many of those living close to the plant collapsed dead in the streets. Those who reached the hospital arrived breathless with lungs filled with water and suffering from convulsions. The doctors present in the hospital were ill- 
informed and inadequately prepared, while the UCC doctors claimed, 'it's just like tear gas'. The death toll soon rose so much that the assistants were told to stop counting.

The following morning, the narrow streets in the Old Town were filled with dead bodies. At the railway station, an entire group of gypsies were found dead. Many bodies were collected and taken to the Muslim churchyard or the Hindu crematorium, others were simply dumped into the Narmada River by the police without registration. The town was completely silent, people were too sick to work or to even move. Trading stopped and farmers from outside districts stayed away. 4000 dead cattle had to be disposed of.

More than 500,000 people were exposed to the gases. The still-birth rate increased by $300 \%$; peri- and neo-natal mortality rates increased by $200 \%$. While the official death figure in 1991 was stated as 3,928, it is more probable that at least 8,000 died within the first days (Eckerman 2005b).

\subsection{Long term health effects}

For several years following the accident, different opinions existed about the long-term effects of the leaked chemicals. UCC consistently maintained that MIC could not cause permanent impairment - which was an opinion shared with various sections within scientific and official establishments. However, survivors' organizations and activists have fought to have their opinion acknowledged. It is their view that thousands of people have been left permanently disabled due to the gases. In the medical sphere, the term 'syndrome' refers to a combination of several symptoms and findings. Thus the 'Bhopal syndrome' has been used to refer to the combination of symptoms and damage to human organs that the gas leak caused.

In 1986, Dr. C.R. Krishna Murti, president of the commission that investigated the accident, stated that between 30,000 and 40,000 people had persistent disabilities (Kulling \& Lorin 1987) and identified them within the following categories:

- Those who were so seriously disabled that they could not work and who often experienced difficulties in walking or cycling due to bad coordination.

- Those who had some persistent dysfunction in the airways and suffered from chronic pulmonary insufficiency, but still managed to work.

- Those who seemed well but who had a strongly decreased resistance to infections, especially in the lungs and airways.

In 1992, the Permanent People's Tribunal on Human Rights recommended that an international medical commission should assess the long-term effects. In 1994, the International Medical Commission on Bhopal (IMCB) met. According to the material and testimonies presented to IMCB, the experi- 
ences varied at different distances from the plant. Those living closest to the factory suffered from very severe, acute, as well as long-term issues. For some, the symptoms became more aggravated over time. Those living a little further away, or who had spent the night on the second or third floor of a building, recovered better with only a slight degree of breathlessness remaining. Those living on the slopes of the southern part of the Old Town were left with no remaining symptoms, but continue to suffer from the traumatic memories and worry about the effects on their future generations. These findings were verified to some extent by investigations undertaken by IMCB (Dhara 1992, Cullinan et al. 1997, Eckerman 1996).

The impression gained is that the information provided by UCC as well from the Indian Government (GoI) and ICMR was meant to portray a picture of injuries being of a mild degree only. The long-term effects were not illustrated in the legal process that followed the accident. There seems to be several reasons for this fact (Eckerman 2005b): UCC wanted to reduce their liability, and many of the leading doctors of ICMR were closely related to UCIL; careless handling of cyanide might be regarded as murder in the US; multinationals did not want mother companies to be responsible for daughter companies - if this were the case, it would affect the global market; the GoI did not wish to alienate multinational capital and they themselves had invited the chemical industries to establish plants in India; there was pressure on the GoI from the local chemical industry which were opposed to any restrictions; and finally, the GoI did not want to spend large amounts of money on health care.

\subsection{Socio-economic effects}

The economic situation of the hardest affected part of the Bhopal population in 1984 can be categorized as a dependence on physical and casual work or cattle for income, and male offspring for support in old age. A survey conducted in late December 1984, found that $75 \%$ of the workforce was incapable of work mainly due to issues of breathlessness (National Institute for Working Life 2001). It was also recorded that many families had lost their stock of cattle. In a later survey conducted in 1985, it was reported that 25,000 families suffered from a total or substantial loss of income (Chauhan 1996). Parents did no longer have sons to support them in old age. Young girls did not get married and would remain dependent on their parents for a living.

\subsection{Compensation from Union Carbide}

In the days following the disaster, American lawyers entered Bhopal and persuaded the victims to file for damages. A short while later, back in the 
US and equipped with the signatures, the legal experts then began proceedings to claim billions of dollars in compensation (ICFTU 1998). However, in March 1985, the GoI passed the Bhopal Gas Leak Disaster Act which handed the government the statutory right to represent all victims in or outside India. This act alone almost completely disempowered the victims from participating in the adjudication process. For UCC, the act was to their great advantage (Shristi 2002).

In 1985, UCC made an offer of US\$ 350 million as a settlement. The Union of India emphatically refused to accept the offer and instead demanded compensation of US\$ 3.3 billion. In February 1989, there were few signs of progress, as UCC denied all liability. However, suddenly it was announced that a settlement had been reached between UCC and GoI: UCC agreed to pay US\$ 470 million in a final settlement of its civil and criminal liability - corresponding to the insurance sum of US\$350 million plus interest (Shristi 2002).

\subsection{Dismantling the plant}

Between 1985 and 1986 the factory was dismantled. Pipes, drums, and tanks from the production unit were cleaned with water combined with a chemical decontaminant, and then sold off to local entrepreneurs. However, the MIC and Sevin plants remain standing and continue to house the control room, the tanks, and storages of various residues. The plant is in decrepit condition with isolation material continually breaking off and spreading over the ground. 350 tons toxic waste remain dumped in bags.

The surrounding area had been used as a dumping site for hazardous chemicals. UCC's own laboratory tests conducted in 1989 revealed that soil and water samples collected from within the factory vicinity were toxic to fish (UCC 1989). The report identified 21 sites within the plant as being highly polluted. Other investigations have revealed chemical contamination in soil, ground water, and vegetables in the larger area (UCC 1985, BGIA 2000, Down to Earth 2003, UCC 1989, Hindu University 2003).

Under the original land lease agreement, UCC was required to clean the factory site before returning it to the government (MacSheoin 2003). While the company did initiate the waste collection process when their stake was sold in 1994, the work was halted. Activists continued to demand for the cleaning of the site along with the solar ponds, where hazardous chemicals were regularly dumped. On several occasions, incineration at different locations was decided, but activists have argued that the incineration process was not safe enough. They are insistent that Dow Chemical (now DowDuPont) should pay. 


\section{Ethical Analysis}

The following section identifies those with whom the responsibility should lie and discusses the ethical rules that ought to have guided those involved. A particular focus is put on highlighting the ethical values that the responsible actors violated.

\subsection{Whose responsibility?}

From an earlier study, the conclusion was drawn that to create the mega-gas leak, it was not enough that water merely entered the tank (Eckerman 2001, 2005a, 2005b, 2011, 2013). The analysis argued that while the water washing theory seems most convincing, the direct cause of the leakage should not be regarded as the most pressing issue. The magnitude of the disaster was dependent on other factors such as: the design and the location of the plant; the lack of emergency plans and information to the population; the low competence of the staff; the lack of information from UCIL and UCC about the gases; and the absence of a possible antidote. There were also conflicts between NGOs, police, health authorities, and scientists which hindered the response efforts. The rehabilitation offers including adequate economic compensation were insufficient. The parties identified as being most responsible for the magnitude of the disaster were the two main owners, UCC and the GoI, and to some lesser extent, the MP Gov.

Even if the direct cause was sabotage, the leakage could have been prevented. If the personnel management policy had been better, no 'disgruntled worker' or 'negligent employees' would have existed. The impact on health could also have been reduced if the residents had been given reliable information on how to behave in the case of a leakage and if they had been warned by the siren earlier in the night. As it is probable that in the area closest to the factory, where the most serious health effects occurred, hydrogen cyanide was present in considerable concentrations, early treatment with sodium thiosulphate would have mitigated the effects on the health of those living in that sector. The effects on health caused by the leakage could also have been mitigated if the medical, social, and economic rehabilitation had been adequate.

\subsection{Ethical principles}

While often viewed as a necessary foundation for any society, ethics can be interpreted and defined in several ways. One such definition characterizes ethics as a particular set of rules offering guidance on how to behave towards each other. A disaster such as the Bhopal gas leak provides points to violations of ethical principles. The set of four principles outlined below incorpo- 
rate the moral view of these authors, and are applied in the analysis of the actions undertaken by the main actors involved in the Bhopal disaster.

\subsubsection{The Golden Rule}

The Golden Rule, or the ethical principle of reciprocity, is a rule of altruism that seems to have existed since the emergence of early cultures. Confucius (551-479 BC) wrote "that which you do not desire, do not do to others" (Eno 2015). The New Testament (Matthew 7:12) says: "Therefore whatever you desire for men to do to you, you shall also do to them". Hippocrates (460-370 BC) formed the first ethical rules for physicians, nowadays often complemented with a rule stating, "above all, do no harm" (Smith 2005).

\subsubsection{Human rights to life, bealth, and bealthy environments}

The substantial list of declarations on human rights contains rules for nations and individuals regarding behavior, in an effort to achieve a smooth and peaceful co-existence. One might expect that the listed human rights would include the right to life and health as well as the right to a healthy environment. However, in the International Bill of Human Rights, nothing is mentioned directly about those particular themes (UN 1993).

The International Covenant on Economic, Social and Cultural Rights is clearer on the topics, and along with addressing the right to form and join trade unions includes the need for the improvement of environmental and industrial hygiene (OHCHR 1966).

The OECD Guidelines for Multinational Corporations have existed since 1976 and are signed by 35 governments (Saltas 2002). The principles were revised in 2000 to include declarations regarding the environment and corruption, in addition to human rights, the rights of the employees, consumers' interest, etc. The OECD rules are voluntary, and there is no possibility of punishment.

Meanwhile, the international non-governmental community has developed its own declarations. In 1996, the Charter on Industrial Hazards and Human Rights was published by the Permanent Peoples' Tribunal following a series of international conventions and guided by a number of similar declarations (Permanent Peoples' Tribunal 1996). The Declaration on Peoples' Right to Safety was produced at the $5^{\text {th }}$ and $6^{\text {th }}$ World Conferences on Injury Prevention and Control in New Delhi 2000 and Montreal 2002 (6th World Conference on Injury Prevention and Control 2002). The participants of the convention argued that the right to safety should be endorsed by the United Nations.

It took more time for the UN society to finally realize the need of guidelines for companies. The Guiding Principles on Business and Human Rights: 
Implementing the United Nations 'Protect, Respect and Remedy' Framework (UN 2011) were developed addressing the issue of human rights relating to transnational corporations and other business enterprises.

\subsubsection{The Precautionary Principle}

Pharmacists or doctors would rarely if ever conclude that 'since no evidence of negative side-effects is known, as no research has been undertaken, the medication can be prescribed'. Instead they would more likely state 'since we are not yet fully aware of potential negative effects, we cannot prescribe the medication'. When referencing the potential leakage of chemicals into the environment, this is called the principle of precaution (UNEP 1992). If any negative side-effects of a substance are suspected, precautionary measures should be taken even if some cause and effect relationships have not been fully established scientifically.

\subsubsection{Sustainability}

Including future generations among Confucius' 'others', leads us to the subject of 'sustainable development'. The most common definition comes from the Brundtland Report (Brundtland 1987) which states that: "Sustainable development is development that meets the needs of the present without compromising the ability of future generations to meet their own needs".

The four principles of the Natural Step Foundation (2016) delve deeper into this topic and state:

In a sustainable society, nature is not subject to systematically increasing

1. concentrations of substances from the earth's crust $[\ldots]$

2. concentrations of substances produced by society $[\ldots]$

3. degradation by physical means $[\ldots]$

4. And in that society there are no structural obstacles to people's health, influence, competence, impartiality and meaning.

These principles constitute a framework for all kinds of organizations and companies, as well as authorities, to use when planning for future sustainability.

\subsection{Ethical responsibilities of the corporation}

It is widely held that UCC alone was responsible for the accident to happen and was negligent in its handling of the aftermath. The surviving victims regard the company as a capitalistic monster that did not take the lives of human beings into consideration (Figure 3). Morehouse (1993) concludes that the behavior of UCC was immoral. 


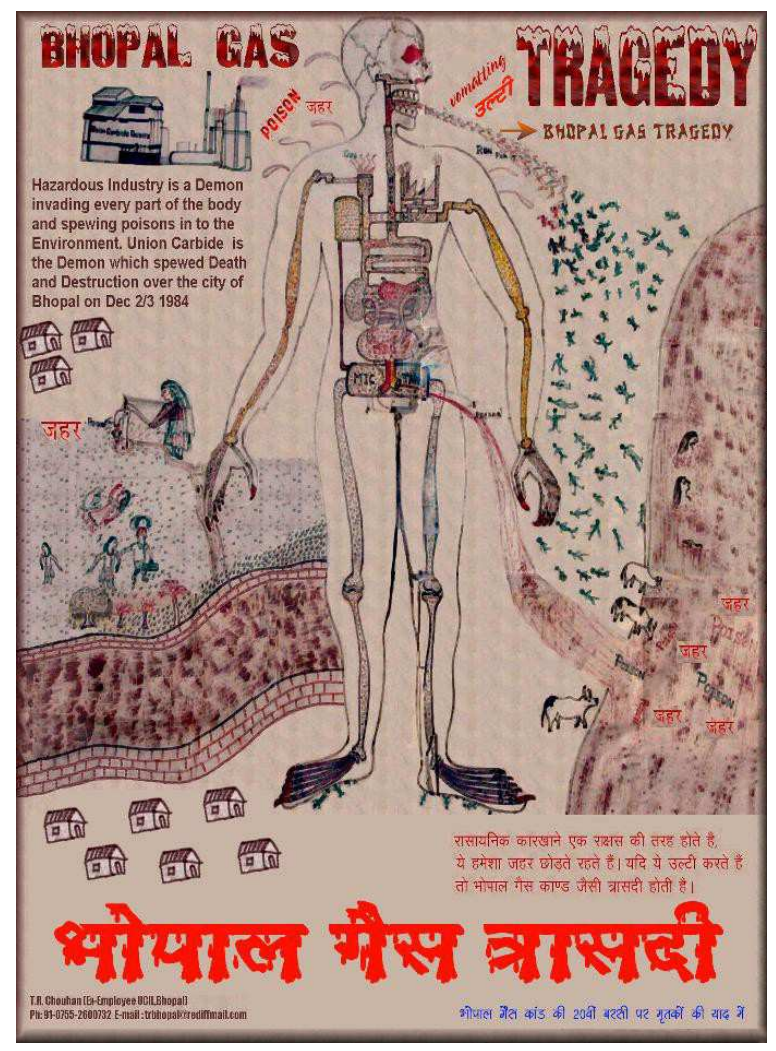

Figure 3. Bhopal Gas Tragedy, painting by T.R. Chouhan, earlier employed operator at the UCIL plant in Bhopal. The hazardous industry is depicted as a demon invading the body and spreading poisons into the environment. Reproduced with permission by T.R. Chouhan.

Although UCIL has admitted that the sabotage theory was false (Morehouse 1993), and the management shortcomings are well known to the public, UCC still maintains the theory that it was a disgruntled worker who caused the leakage.

Following the accident, it seems likely that UCC did their best to hide the truth and disclaim responsibility. Supporting treatment with sodium thiosulphate would have confirmed that other compounds with serious and wellknown effects on health had been released. The company firmly denied that MIC could have any long-term health effects. Prior to the accident, maintaining the Bhopal plant in a safe condition would not have involved a major investment for a large corporation such as UCC. Sufficiently compensating 
the survivors would likewise not have been too costly. It is clear that they regarded shares and profit as more valuable than human beings.

It was in the interests of the company not to recognize the serious effects of the gases as the amount of compensation the company would ultimately be liable to pay would depend on the extent of the injuries. In addition, the GoI had - and still has - an interest of keeping the compensation claim low as a high claim would discourage other chemical industries from establishing plants in the country.

Dow Chemical (now DowDuPont), which took over UCC in 2001, denies all responsibility for the victims and tries to distance itself from current proceedings. This differs significantly to a case described on the website of The Mesothelioma Center (www.asbestos.com). The multinational corporation ABB acquired in 1991 the US based Combustion Engineering, which had used asbestos as insulation material until the 1970s. Having taken control of the company, $\mathrm{ABB}$ assumed responsibility for the compensation claims from those who became ill as a result of exposure to the asbestos. In 2001, it became possible for people who had not yet any symptoms to claim compensation. In 2006, a trust of 1.43 billion USD was established to settle pending and future asbestos claims.

This paper argues that UCC and UCIL violated the four ethical rules chosen by the authors. Adhering to the Golden Rule would lead one to ask themselves: What risk would be acceptable for my family and for my grandchildren? This would have led to a proper risk-benefit analysis, and more than likely have resulted in a different design and location for the plant. The different declarations on human rights are important statements about what can be accepted in a civilized society. In the Bhopal case, one can raise doubts as to whether the corporations were concerned with such declarations.

The precautionary principle would have led one to prevent Sevin being produced under such circumstances. It would certainly have cancelled any plans for opening a MIC plant in the first place as knowledge about the adverse effects of carbaryl had already existed in the 1980s. The $2^{\text {nd }}$ principle for sustainability was also violated. The principle states that "in a sustainable society, nature is not subject to systematically increasing concentrations of substances produced by society" (see above) and demands that chemical industry should have complete control of every molecule of the substance it uses.

\subsection{Ethical responsibilities of the government}

The negligence of both the GoI and MP Governments has been highlighted as an important factor contributing to the leakage. In the aftermath, the GoI itself assumed the role of the victims' lawyer and therefore cannot deny its 
share of responsibility. Furthermore, Indian society as a whole can be seen to have violated the $4^{\text {th }}$ principle for sustainability, as stated above. The affected population was the poorest of the poor and a great proportion was Muslim. Little interest in the welfare of the affected population has been shown by the authorities (Eckerman 2005b). The caste system and prevalent religious values reinforcing Muslims' lower status may also have contributed to the neglect.

It is noticeable that the attitude of the elite and the ruling class in India towards those on the poorer rungs of society share many similarities with other countries experiencing equally large economic gulfs between different classes. This class issue is relevant on a global as well as a national level. Citizens of poorer countries are more exposed to environmental hazards than those of rich countries, while in each respective country the poorer sections of the population are typically more exposed than the richer.

With a focus on poorer countries in particular, Cassels (1993) investigated the relationship between transnational corporations and governments. He describes its complexity and highlights the dependency that the national governments have on the corporations. This results in a compromising situation in which environmental and safety concerns will inevitably be balanced against the danger of the flight of capital. "What limited power the state does have to respond to the demands of workers and social activists is just that limited" (Cassels 1993).

In 1992 The Permanent Peoples' Tribunal in Bhopal concluded that fundamental human rights had been grossly violated by the Indian government in relation to several articles in the various international declarations concerning human rights (UN 1993). A large number of national governments have ratified those declarations and many make serious attempts in following them. Therefore, there exists the possibility to prosecute at the International Tribunal for Human Rights in The Hague should a country continue to violate such terms.

\subsection{Ethics of non-governmental organizations}

While the local trade unions were the first to voice concerns regarding the hazards at the Bhopal plant, we do not know whether they were aware of plans for the closure of the plant or not. It is likely that there would have been forceful protests against the risks of unemployment due to the closure, although from an environmental perspective, closure would have absolutely been the best solution.

In the aftermath of the leakage, several thousand people in total must have been involved in helping the victims of Bhopal. As many of these were experts in different fields, the total knowledge contributed by the NGOs was 
likely to have been extensive. Many of the NGOs also had contacts with the WHO and other organizations within the United Nations. Their efforts have led to clinics being opened which are chiefly financed through contributions from the civil society. For example, in 1996, the Sambhavna Trust Clinic for gas victims and those exposed to polluted ground water opened, and in 2005, the Chingari Trust founded a rehabilitation center for handicapped children.

The NGOs goals are usually in accordance with the Golden Rule and corresponding with basic human rights, whereas the environmental organizations generally align themselves with the precautionary principle and sustainability. However, the power and influence of each group is much less significant than that of the corporations or governments, resulting in their efforts falling short.

\section{Preventing 'New Bhopals'}

\subsection{Lessons from the Bhopal catastrophe}

A government survey in the aftermath of the catastrophe identified over 7,000 potentially hazardous plants in the country (Asia ' 92 1992). In 1995, it was reported that, of some 9,000 industrial units screened by the Delhi Pollution Control Committee, only 283 had installed effluent treatment plants. Furthermore, $70 \%$ of India's water resources were found to be polluted. These findings along with the numerous investigations into the disaster led to the approval of improved laws and regulations in India. However, few have been implemented.

Due to the complex nature of the political dynamics within India, both the state and central governments have been able to shift the blame to one another for the continued failure of the regulations being implemented. The Indian government remains keen on continuing the establishment of chemical industries within the country. Several incidents have demonstrated how decisions regarding further industrial development have been expedited, without due consideration for the opposition or any anticipated environmental effects (Asia '92 1992). Shristi (2002) also points out that while the laws and regulations proposed address how to manage the toxicity and the waste, the processes that lead to the hazards are not examined. He argues that the laws have provided the government with a sense of security, and, thereby, have legitimized the continuance of a toxic legacy.

The companies who choose to establish themselves within the country have learned from the Bhopal case, and have acted to protect themselves from 
repeat incidents. An agreement between industrial giant $\mathrm{Du}$ Pont and the Indian government included the following statement relating to the company's representatives, who will be harmless from any claims made in the Republic of India against representatives of $\mathrm{Du}$ Pont or its assignees alleging bodily harm or death sustained as a direct result of, or in direct connection with, the performance of this Agreement.

On the other side, the International Labour Organisation (ILO) and other inter-state organizations have also acted, by means of conventions and declarations, to ensure that companies adhere to sufficient standards when operating in foreign countries (Sambhavna 1998). The Bhopal Resolution of the European Parliament, for example, calls upon European firms to maintain levels of safety abroad that are comparable to those in place in their home operations. Another movement in the form of Corporate Social Responsibility (CSR) has strived to integrate self-regulation within a company's business model. The aim is to increase long-term profits through positive public relations, high ethical standards to reduce business and legal risk, and shareholder trust by taking responsibility for corporate actions.

It is not yet known whether these laws, regulations, conventions, and declarations will be sufficient in preventing another Bhopal disaster. As long as governments fail to implement the appropriate laws and regulations, no change can be expected. After 33 years the Bhopal catastrophe is not forgotten, and new material is continually being produced. Documentary films support the NGOs in their work for human rights and the environment, while scientific papers, like this one, and new books (Bloch 2016) help us to learn valuable lessons.

\subsection{Small 'Bhopals' happen all the time}

The Bhopal Gas Leakage has become a symbol of transnational corporate negligence towards human beings and has thus served as a wake-up call. Despite this, industrial disasters continue to occur in India as well as in other industrialized parts of the world - each with mechanisms similar to the Bhopal catastrophe. The accidents most often occur in and affect countries outside those in which the international companies are headquartered, and happen most typically in countries where production regulations are less stringent than in their 'home' country. The affected countries generally have weak trade unions and poorly developed occupational healthcare, which have little influence on the work environment.

Such similarities make it appear as though the catastrophes could have been predicted and prevented. The companies involved have typically reacted in similar patterns - by disputing their own role in the accident, rejecting any health effect claims, and being reluctant to compensate the victims financial- 
ly. Although they are far from the severity of Bhopal, the sheer number of chemical accidents which have occurred since 1984 could well make a case for them to be considered a public health problem.

\subsection{The roads towards prevention}

To prevent industrial hazards, regulations and declarations are necessary but are not effective alone. The driving force for companies is financial, rather than ethical or moral. The economic pressure that can actually result in change comes from two directions: from the legal system, by means of fines, taxes, etc., and from the consumer side, i.e. the civil society.

A strong legal system requires a state that is democratic and transparent, with little corruption and it is the task of transnational organizations like the $\mathrm{UN}, \mathrm{EU}, \mathrm{OECD}$ etc. to support and demand development in this direction. Today, the development in some countries is in fact progressing in the opposite direction. A conflict often emerges between a workers' demand for employment and a society's desire to reduce pollution. This conflict seems to have found a solution where trade unions start to co-operate with employers and governments to make the plants more environmentally friendly.

Further pressure from the civil society might be effective as long as there is real competition in the market - which is not always the case at present. If a transnational company maintains ownership of the fully chain of food productions, from seeds, fertilizers, pesticides and processing to packaging and selling, and if its market is worldwide, there might be very little choice for the consumer - limiting their influencing power. In that sense, consumers' organizations have to cooperate worldwide to effectively make changes. Having said that, sometimes the companies themselves understand that a society's positive opinion of their organization is a valuable asset, leading them to change their corporate image. Many industry leaders also share concerns about possible hazards and understand that a change must take place. There are several methods for planning and avoiding hazards for the companies that are prepared to change their focus from short to long term planning.

\section{Conclusion}

The two most important factors leading to the catastrophic gas leak in Bhopal were identified as the design of the plant and the company's policy on cutting back on expenses. The negligence of both the company and governmental authorities in the aftermath of the accident were seen to have worsened the impact of the leakage on people's lives. 
The case shows that an ethical analysis of industrial accidents should not focus on individuals, but on the responsibilities of companies as well as national and local authorities. A society that is continuously and increasingly breaking the ethical rules can be regarded as an un-ethical society, while a company that has accepted these rules and strives to follow them, is on the right path.

The analysis shows that ethical rules, such as the Golden Rule on not harming others, human rights, the precautionary principle, and the principles for a sustainable society were violated by both UCC and UNCIAL, while the Indian authorities violated, in particular, the 4th principle for sustainability. The paper has also shown that the prevention of industrial hazards is possible but that it requires a strong legal system, which in turn demands democratic and transparent state governance. Several planning tools exist for companies to utilize in order to reduce the risks of future hazards.

Regarding industrial hazards to public health two antipodes exist: the industries on one side, and the trade unions and non-governmental organizations, working on behalf of human rights and environmental concerns, on the other. While it is common for NGOs and trade unions to fight for what is believed best for human beings, it must be realized that this is not the primary goal for a company. On behalf of the workers and the environment, the NGOs and trade unions typically demand low levels of income disparity, strong employees' rights legislation, manpower-rich companies, effective water and soil protection, and the ability to voice concerns regarding the work environment and the environment as a whole. The company on the other hand, in their pursuit of increased profits, finds it more advantageous to have fewer employees, an ease in hiring and firing laborers, an uncertain labor market (which incentivizes those employed to work harder and refrain from protest out of fear of becoming redundant), and low demands on the work environment and natural environment.

While it is beneficial for a country to strive for increased economic development to improve its citizen's access to education, health care, and public health, it is important to ensure that the methods of achieving the increased prosperity do not adversely affect its citizens. Foreign investments might be a quick way to reach development but often brings with it harmful consequences. It is the task of the government to strike a balance between both needs. Politicians should put the interests of the people, both those of current and future generations, first. NGOs, like trade unions, environmental organizations, and consumers' organizations, should be regarded as resources, not as troublemakers.

Finally, along with the consequences to both the public and corporations discussed above, manmade catastrophes can also result in personal consequences. The UCC chairman and CEO Warren Anderson, together with a 
technical team, immediately travelled to India having been made aware of the accident. Upon arrival, Anderson was placed under house arrest by the Indian police and was threatened by the government to leave the country within 24 hours. For the rest of his life he was forced to live at a secret address, and never appeared in the Indian courts. The last lawsuit in USA was dismissed in 2012. Anderson did not have much time to enjoy life free from the legal scrutiny before he died in 2014.

\section{Further Reading}

Further information can be found in the many books published on the Bhopal tragedy, such as Chouhan 1994, D’Silva 2005, Eckerman 2005b, Hanna et al. 2005, Lapierre \& Moro 2001, and Bloch 2016, while a documentary Bbopal: A Prayer for Rain, directed by R. Kumar in 2014, is available on DVD. More information can also be found at the following websites:

- Bhopal Gas Tragedy Information. Union Carbide Corporation: www.bhopal.com

- Bhopal Medical Appeal: www.bhopal.org

- International Campaign for Justice in Bhopal: www.bhopal.net

\section{References}

6th World Conference on Injury Prevention and Control: 2002, Declaration on People's Right to Safety, Montreal, Canada: 6th World Conference on Injury Prevention and Control.

Asbestos.com: 2016, 'Combustion engineering', [availabe online at: http://www.asbestos.com/companies/combustion-engineering.php, accessed 3 August 2017].

Asia '92: 1992, 'Third Session on Industrial and Environmental Hazards and Human Rights', Permanent People's Tribunal. Findings and Judgements Bhopal, 19-24 October, Bhopal to Bombay (India).

BGIA: 2000, Union Carbide Disaster in Bhopal. Fact sheet. 16th Anniversary of the December 2-3, 1984, Bhopal: Bhopal Gas Pidit Mahila Udyog Sangathan; Bhopal Group for Information and Action.

Bloch, K.: 2016, Rethinking Bhopal. A Definitive Guide to Investigating, Preventing, and Learning from Industrial Disasters, Amsterdam: Elsevier.

Brundtland, G.: 1987, Our Common Future, Oxford: Oxford University Press.

Cassels, J.: 1993, The Uncertain Promise of Law: Lessons from Bhopal, Toronto: University of Toronto Press.

Chauhan, P.: 1996, Bhopal Tragedy. Socio-legal Implications, Jaipur, India: Rawat. 
Chouhan, T.R.: 1994, Bhopal: The Inside Story. Carbide workers speak out on the world's worst industrial disaster, New York: Apex Press.

Cullinan, P.; Acquilla, S. \& Dara, V.R.: 1997, 'Respiratory morbidity 10 years after the Union Carbide gas leak at Bhopal: a cross sectional survey', BMJ, 314 (7077), 314-338.

Delhi Science Forum: 1985, Bhopal Gas Tragedy, New Delhi: Delhi Science Forum.

Dhara, V.: 1992, 'Health effects of the Bhopal gas leak: A Review', Epidemiol Prev, 14, 22-31.

Down to Earth: 2003, 'Foul Debris. The UCIL plant is still a health hazard' [availabe online at: http://www.downtoearth.org.in/coverage/foul-debris-13794, accessed 22 September 2016].

D'Silva, T.: 2006, The Black Box of Bhopal: A Closer Look at the World's Deadliest Industrial Disaster, Victoria, BC, Canada: Trafford.

Eckerman, I.: 1996, 'The Health Situation of Women and Children in Bhopal. Report for The International Medical Commission on Bhopal', International Perspectives in Public Health, (no. 11-12), 29-36.

Eckerman, I.: 2001, Chemical Industry and Public Health. Bhopal as an example, Gothenburg: Nordic School of Public Health.

Eckerman, I.: 2005a, 'The Bhopal Gas Leak: Analysis of causes and consequences by three different models', Journal of Loss Prevention in the Process Industries, 18, 213-217.

Eckerman, I.: 2005b, The Bhopal Saga. Causes and Consequences of the world's largest industrial disaster, Hyderabad: Universities Press (India).

Eckerman, I.: 2011, 'Bhopal Gas Catastrophe 1984: Causes and Consequences', in: J. O. Nriago (ed.), Encyclopedia of Environmental Health, Burlington: Elsevier, pp. 302-316 [updated version 2013 available online at: http://www.sciencedirect.com/science/article/pii/B9780124095489019035, accessed 23 Sept 2016].

Eno, R.: 2015, The Analects of Confucius, XV:24 [available online at: http://www.indiana.edu/ p374/Analects_of_Confucius_(Eno-2015).pdf, accessed 21 Sept 2016].

Hanna, B.; Morehouse, W. \& Sarangi, S: 2005, The Bhopal Reader. Twenty Years of the World's Worst Industrial Disaster. New York: Apex Press [availabe online at: http://bhopal.org/, accessed 21 Sept 2016].

Hindu University: 2003, Hinterland. A Special Issue on The Bhopal Gas Tragedy, New Delhi: Department of English, Hindu University.

ICFTU: 1998, Commitments for Sustainable Development. Trade Unions at the Commission for Sustainable Development. Special 'Business and Industry' Segment, Brussels: International Confederation of Free Trade Unions.

ICFTU-ICEF: 1985, The Trade Union Report on Bhopal, Geneva: International Confederation of Free Trade Unions-ICEF.

Jones, T.: 1988, Corporate killing. Bhopals will happen, London: Free Association Books.

Kalelkar, A.S.: 1988, Investigation of Large-magnitude Incidents: Bhopal as a Case Study, Cambridge, MA: A.D. Little.

Kulling, P. \& Lorin, H.: 1987, The Toxic Gas Disaster in Bhopal December 2-3, 1984, Stockholm: Försvarets Forskningsanstalt (National Defence Research Institute) [In Swedish].

Kumar, C. \& Mukerjee, S.: 1985, 'Methyl Isocyanate: Profile of a killer gas', in: Bhopal: Industrial genocide?, Hong Kong: Arena Press.

Lapierre, D. \& Moro, J.: 2001, It Was Five Past Midnight in Bhopal, New Delhi: Full Circle. 
MacSheoin, T.: 2003, Asphyxiating Asia. Mapusa, Goa, India: Other India Press.

Morehouse, W.: 1993, 'The Ethics of Industrial Disaster in a Transnational World: The elusive quest for justice and accountability in Bhopal', Alternatives: Global, Local, Political, 18 (4), 475-504.

National Institute for Working Life: 2001, Scientific Basis for Threshold Limit Values. Mebylisocyanate and Isocyanacid, Stockholm, Sweden: National Institute for Working Life.

Natural Step Foundation: 2016, 'The Natural Step Framework' [availabe online at: http://www.thenaturalstep.org/approach/, accessed 3 Aug 2017].

OHCHR (Office of the United Nations High Commissioner for Human Rights): 1966, International Covenant on Economic, Social and Cultural Rights [available online at: http://www.ohchr.org/EN/ProfessionalInterest/Pages/ CESCR.aspx, accessed 20 Sept 2016].

Permanent People's Tribunal: 1996, Charter on Industrial Hazards and Human Rights [available online at: https://www.globalpolicy.org/component/content/ article/212/45285.html, accessed 23 Sept 2016].

Ramachandran, C.: 1994, 'Immediate Post Industrial Disaster Management', in: Refresher course for Top Executives. Management of Chemical Accidents, Bhopal: Disaster Management Institute.

Saltas, A.: 2002, 'Can UN regulate the transnational companies? Let the UN-organ UNCTAD check the companies' direct investments in developing countries', Stockholm: Sodertorns Hogskola.

Sambhavna: 1998, The Bhopal Gas Tragedy 1984 to ? A report from the Sambharna Trust, Bhopal, India, Bhopal: Bhopal People's Health and Documentation Clinic.

Shristi: 2002, Surviving Bhopal. Toxic present - toxic future. A report on Human and Environmental Chemical Contamination around the Bhopal disaster site, New Delhi: The Other Media.

Smith, C.M.: 2005, 'Origin and uses of primum non nocere - above all, do no harm!', Journal of Clinical Pharmacology, 45(4), 371-7.

Subramaniam, A.: 1985, 'Bhopal - The dangers of diagnostic delay', Business India, (August), 12-25.

UCC: 1976, 'Methyl Isocyanate', Union Carbide Document No. F-41443A - 7/76, New York: s.n.

UCC: 1985, Bhopal Methyl Isocyanate Incident. Investigation Team Report, Danbury, CT: Union Carbide Corporation.

UCC: 1989, Presence of Toxic Ingredients In Soil/Water Samples Inside Plant Premises, Union Carbide Corporation.

UCIL: 1978, Carbide Monoxide, Phosgene and Methyl Isocyanate. Unit Safety Procedures Manual, Bhopal: Union Carbide India Limited.

UN: 1993, The International Bill of Human Rights, New York: United Nations.

UN: 2003, Norms on the Responsibilities of Transnational Corporations and Other Business Enterprises with Regard to Human Rights, s.l.: United Nations.

UN: 2011, Guiding Principles on Business and Human Rights: Implementing the United Nations 'Protect, Respect and Remedy' Framework, s.l.: United Nations.

UNEP: 1992, Rio Declaration on Environment and Development [available online at: http://www.unep.org/Documents.Multilingual/Default.asp? DocumentID=78 \&ArticleID=1163, accessed 22 Sept 2016].

Varadarajan, S.: 1985, Report on Scientific Studies on the Factors related to Bhopal Toxic Gas Leakage, New Delhi: Indian Council for Scientific and Industrial Research. 
Ingrid Eckerman:

Swedish Doctors for the Environment, Stockholm, Sweden;

Ingrid@eckerman.nu

Tom Børsen:

Department of Development and Planning, Aalborg University Copenhagen,Denmark;boersen@plan.aau.dk 